\title{
Aerobic Epoxidation with a Polyoxomolybdate Nanoball
}

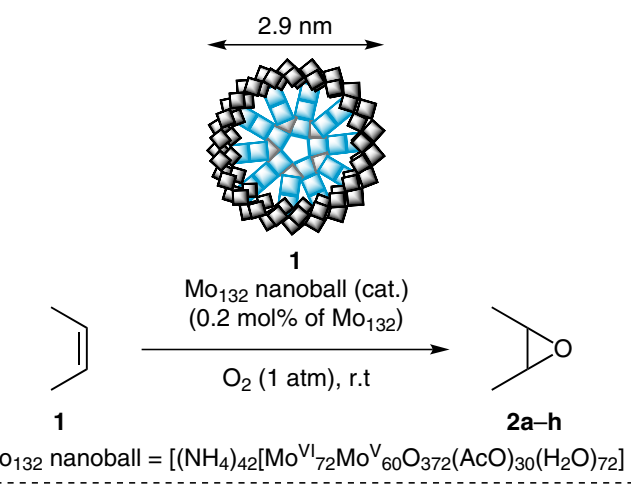

Selected results:

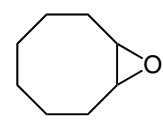

$2 \mathrm{~h}, 96 \%$ yield

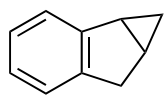

$2 e$

$4 \mathrm{~h}, 89 \%$ yield<smiles>C1CCC2OC2C1</smiles>

$3 \mathrm{~h}, 92 \%$ yield<smiles>CCCCCCC1CO1</smiles>

$2 f$

$4 \mathrm{~h}, 90 \%$ yield

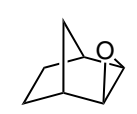

2c $2 \mathrm{~h}, 95 \%$ yield

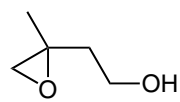

$2 \mathrm{~g}$ $5 \mathrm{~h}, \mathbf{9 6 \%}$ yield<smiles>CC1(c2ccccc2)CO1</smiles>

$2 d$ $4 \mathrm{~h}, 94 \%$ yield

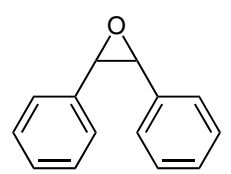

$2 \mathrm{~h}$

$5 \mathrm{~h}, 97 \%$ yield
Significance: The aerobic epoxidation of olefins in aqueous solution takes place with the Keplerate-type polyoxomolybdate $\mathrm{Mo}_{132}$ catalyst $\mathbf{1}$ under oxygen to give the corresponding products 2a-h in up to $97 \%$ yield. In contrast, $\mathrm{MoO}_{3}$, $\left(\mathrm{NH}_{4}\right)_{6} \mathrm{Mo}_{7} \mathrm{O}_{24}$, and $\mathrm{Na}_{2} \mathrm{MoO}_{4}$ showed no catalytic activity under similar conditions.

\section{Gategory}

Polymer-Supported

Synthesis

\section{Key words}

epoxidation

polyoxomolybdate nanoball

aerobic conditions

heterogeneous catalysis

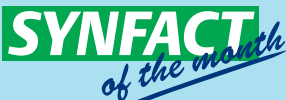

